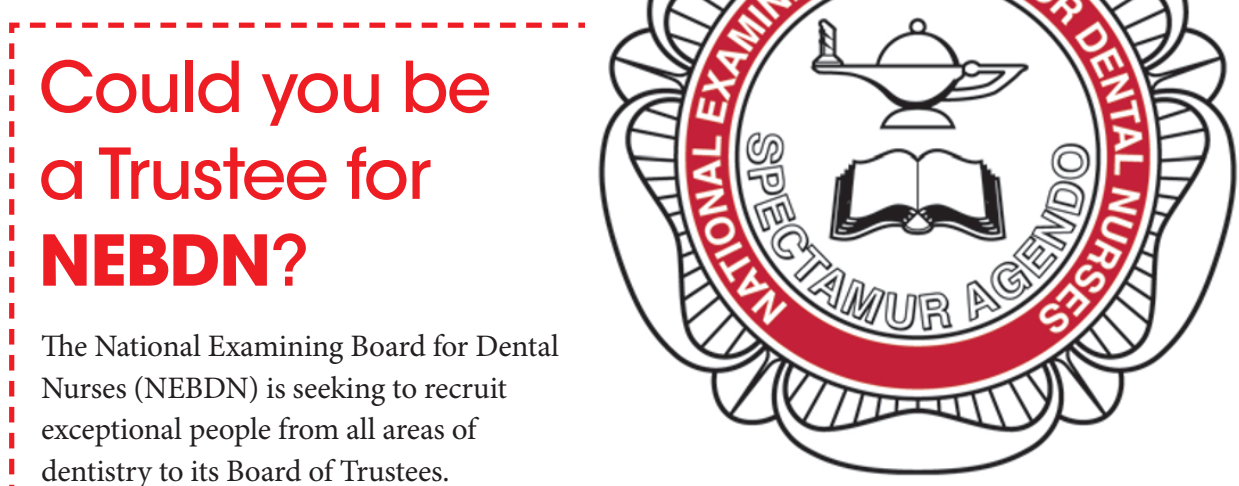
dentistry to its Board of Trustees.

NEBDN works throughout the UK and Ireland to deliver high quality qualifications for dental nurses. Its mission is to improve the quality of education and training for dental nurses to promote patient safety and support effective dental practice.

Having recently been through a significant period of change, NEBDN now wishes to strengthen the Trustee Board to support growth and development in a changing external environment. This is an exciting opportunity to get involved in improving dental nurse education and training in the future.

Professor Nairn H. F. Wilson, Emeritus Professor of Dentistry and NEBDN Trustee, said: 'The primary purpose of a Trustee in a not-for-profit charity such as NEBDN is to ensure that the organisation acts in the best interest of the beneficiaries. In the case of NEBDN, these are dental nurses and, in turn, the professions of dental nursing and dentistry. To achieve this goal, Trustees must individually and collectively oversee, in an objective, free of conflict manner, the most efficient and effective use of available resources and volunteer support.

'Thanks to a number of arrangements and circumstances unique to the UK, including the sterling work of the NEBDN, dental teams in Britain are supported by exceptionally well-qualified nurses. Indeed, UK qualified dental nurses are amongst the best in the world.'

Becoming a Trustee for NEBDN is an excellent opportunity, whether you are looking to become a trustee for the first time or you have previous experience of Boardlevel work.

Trustees are required to commit to around six Board meetings per year held either at the charity's headquarters in Preston, Lancashire or in London. In addition, there are two or three supplementary meetings of the Board or its sub-committees annually and ongoing information exchange, which requires a regular time commitment each month. This is an unremunerated role although expenses will be paid for attendance at meetings.

For further information and to download an application pack visit www.nebdn.org, email Laura Oddie, Executive Assistant to the Chief Executive at laura.oddie@nebdn. org or telephone 01772 429994. The closing date for applications is Friday 7 April 2017.

\section{Will you be in Manchester this May?}

This year's British Dental Conference and Exhibition will be held at Manchester Central Convention Complex from Thursday 25 to Saturday 27 May. The three-day event will offer you the chance to gain verifiable $\mathrm{CPD}$, network with your peers and learn about the latest innovations and technologies at the exhibition.

At the Friday night party you and your team can enjoy handmade, rustic dishes and bespoke cocktails at Artisan on Manchester's Avenue North, then dance the night away with a live band.

If your principal is a BDA expert member, you may be able to attend for free. For more information and to book, visit www.bda.org/conference.

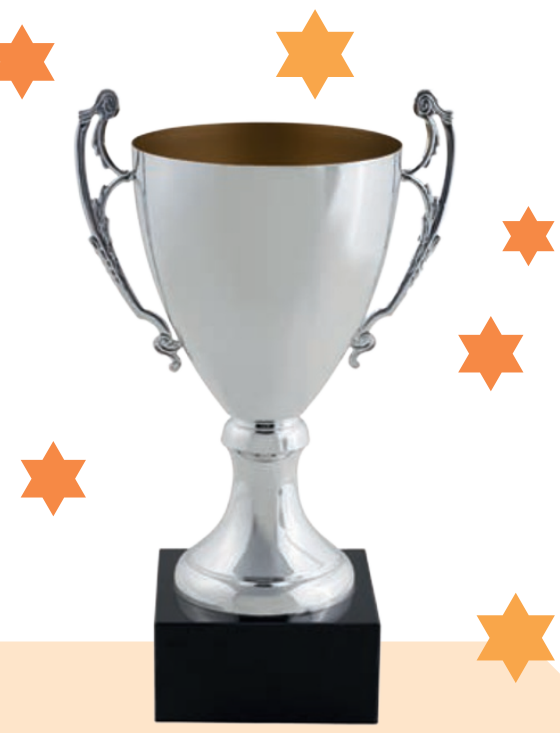

effective plan for continuing personal and professional development throughout their career.'

For many years, BSDHT has sponsored a prize for each dental hygiene and therapy school in the UK to be awarded to their choice of student who they believe has excelled in their studies. Through BSDHT's new collaboration with Henry Schein, to further enhance and recognise these efforts, one winner from each school will now be considered for the overall 'Student of the Year' award.

The prize will include travel, accommodation and entrance into the BSDHT OHC and the spectacular 'Student of the Year' trophy. 